\title{
Benchmarking and tracking domestic gas and electricity consumption at the local authority level
}

\author{
Jonathan Morris • David Allinson - John Harrison • \\ Kevin J. Lomas
}

Received: 17 March 2015 / Accepted: 2 September 2015 /Published online: 15 September 2015

(C) Springer Science+Business Media Dordrecht 2015

\begin{abstract}
Government, local authority and industry initiatives to improve the energy efficiency of housing stocks are central to national and international commitments to reduce carbon dioxide emissions. To be effective, initiatives need to target homes which, given their location, size, fuel type and occupancy, use more energy than expected. This paper illustrates how energy efficiency benchmarks can be developed that account for these factors and highlights the shortcomings of relying on simple energy consumption statistics. The study uses existing data (with national coverage) and the measured electricity and gas consumption of groups consisting of, on average, 500-700 households to benchmark and track domestic gas and electricity consumption across England. Multiple regression models, which account for $65 \%$ of the variation in domestic gas consumption and $73 \%$ of domestic electricity variation, are used to derive the benchmarks. The actual gas and electricity consumption of each group of homes is compared against the derived benchmark and an energy efficiency index presented. The approach enables changes in energy
\end{abstract}

\footnotetext{
J. Morris $(\bowtie)$

Centre for Energy, Environment and Sustainability, University of Sheffield, Sheffield S1 4DT, UK

e-mail: j.c.morris@sheffield.ac.uk

D. Allinson · K. J. Lomas

School of Civil and Building Engineering, Loughborough

University, Loughborough LE11 3TU, UK

J. Harrison

School of Social, Political and Geographical Sciences, Loughborough University, Loughborough LE11 3TU, UK
}

efficiency to be tracked temporally, for example to assess the effectiveness of government, local authority or industry initiatives. National and city-scale patterns of energy efficiency are also discussed.

Keywords Domestic electricity consumption . Domestic gas consumption · Benchmarking · England . Local authorities

\section{Introduction}

In 2008, as part of a wider international commitment to reduce carbon dioxide emission $\left(\mathrm{CO}_{2}\right)$, the $\mathrm{UK}$ Government set a target to reduce $\mathrm{CO}_{2}$ emissions by $80 \%$ relative to 1990 levels by 2050 (HM Government 2008). This target fits with a wider European Union (EU) identification of improving energy efficiency measures in buildings as a key action to achieve reductions in European-wide $\mathrm{CO}_{2}$ emissions. This is perhaps best exemplified by the recast Energy Performance of Buildings (EPBD) directive (European Council Directive 2010/31/EU) that promotes 'nearly zero' energy building, i.e. a building with a very high energy performance for all new building construction (Commission of the European Union 2010). Although this does not specifically target existing buildings, the recast directive states that European member states are expected to develop policies - using instruments such as target setting - to stimulate the transformation of buildings via refurbishment into very low energy 
buildings (Commission of the European Union 2010). This paper explores the latter in relation to the domestic sector in the UK, which, despite accounting for almost $25 \%$ of national carbon emissions and $30 \%$ of total final energy use (Utley and Shorrock 2008; Kannan and Strachan 2009), has historically not received anywhere near the same attention in terms of regulations and resources through UK legislature to tackle carbon emissions when compared to industrial and commercial sectors (Scott et al. 2014).

Recent years have seen signs that the increasing evidence base surrounding the environmental impact of the UK's housing stock on of carbon emissions is raising awareness for the need to implement residential energy and $\mathrm{CO}_{2}$ reduction policies (Marchard et al. 2015). The UK has incorporated new build directives into national legislation, for example regarding the construction of new housing in the Building Regulations Part L (Raslan 2012). Nonetheless, existing housing is forecasted to account for $70 \%$ of the UK's 2050 housing stock, and whilst there exists significant potential to reduce domestic energy demand by improving the thermal efficiency of the existing housing stock and introducing energy efficient electrical appliances (Firth and Lomas 2009), there is a clear need for tools to benchmark and track energy consumption in the domestic sector to measure progress against carbon targets.

\section{Current policy approaches}

In January 2013, the UK Government replaced a raft of previous domestic sector energy efficiency policies-including the Carbon Emissions Reduction Target (CERT), Community Energy Saving Programme (CESP), and Warm Front (see Mallaburn and Eyre 2014 for a comprehensive review) - with the Green Deal and Energy Company Obligation (ECO) schemes. One of the key developments of the 2013 policies was the focus on stimulating an energy efficiency refurbishment market: under the Green Deal households are to cover the upfront costs of energy efficiency improvements to their house through a loan which is secured on the property and paid back through savings to energy bills (HM Government 2011; Department of Energy and Climate Change [DECC] 2011a; Dowson et al.
2012), whilst the ECO scheme obliges larger energy companies to deliver energy efficiency measures to vulnerable consumer groups and hard-to-treat properties, primarily to tackle fuel poverty ${ }^{1}$ (DECC 2011b; DECC 2013a). Although the general methods used to tackle fuel poverty and reduce energy consumption may be broadly similar-such as the interventions provided under the Green Deal and ECO schemes - the impact on carbon emissions may vary depending on the value households place on increased warmth (Scott et al. 2014; Marchand et al. 2015). In this paper, the focus is on policies to reduce energy consumption, such as the Green Deal, as part of efforts to reduce $\mathrm{CO}_{2}$ emissions.

Identifying energy (in)efficiency

The Green Deal consultation emphasises the role of local authorities in promoting energy efficiency schemes, in part, due to the perceived trust they have from their residents (Institute of Gas Engineers and Managers [IGEM] 2011, DECC 2012), their unique position in communities as an organisation that can act as both a partner or direct provider of Green Deal schemes (DECC 2011a; 2012; 2013b), their local knowledge which should enable them to better identify areas best suited for Green Deal measures and their role in the active promotion of such schemes (DECC 2011b, Bale et al. 2012). That said, previous research on local energy efficiency schemes highlights the need for appropriate data and evidence. For example, Hamilton et al. (2013) state that

the successful delivery and uptake of energy efficiency measures in order to achieve the goal of reducing greenhouse gas emissions ... requires that policies are developed from an empirical foundation built on high quality data (p. 464).

There are signs that the UK Government is now taking steps to produce the 'high quality data' needed to provide this empirical foundation. Beginning with the year 2008, DECC (2013b) now publish annual sub-

\footnotetext{
${ }^{1}$ Fuel poverty is defined in the UK as the situation when a household spends more than $10 \%$ of its income on fuel. However, the 2011 Hills Review has redefined this concept in England so that households are in fuel poverty if their fuel bills are above the national median and their remaining income is below the official poverty line (see DECC 2013b).
} 
national gas and electricity consumption data at Lower Super Output Area (LSOA) ${ }^{2}$ with the stated aim to

Enable councils and others to monitor and target small areas for further interventions as part of their local energy strategies, and enhance the implementation of energy efficiency programmes and thus reduce carbon dioxide emissions (DECC 2013b, p. 2).

DECC re-affirm their commitment to assisting local authorities in energy efficiency strategies, adding (2013b): 'the most significant use of the sub-national consumption data is by local authorities and devolved administrations for targeting and monitoring a range of carbon reduction and efficiency policies' (p. 12).

Annual data releases allow for the monitoring of progress in terms of reductions in energy consumption but may not necessarily identify suitable target areas for energy efficiency programmes. This is because the absolute energy demand alone does not always indicate the potential energy reductions from improving the energy efficiency of the housing stock. For example, areas with larger houses and colder weather will typically have a higher energy demand and the challenge is to identify areas of higher than average household demand after considering factors independent of the level of energy efficiency in the housing stock.

Previous research to identify predictors of energy demand identifies house size, income and weather as key predictors of energy consumption. Baker and Rylatt's (2007) study of 148 houses across Leicester and Sheffield showed that the number of bedrooms accounted for almost $35 \%$ in the variation in household gas and electricity consumption. A similar study of 36 low energy houses in Milton Keynes revealed that the top $30 \%$ of households by income used more energy than the remaining $70 \%$ of households combined (Summerfield et al. 2010a). Furthermore, Summerfield et al. (2010b) observed that a $1{ }^{\circ} \mathrm{C}$ increase in external air temperature leads to an approximate $5 \%$ decrease in energy demand. Taking these factors together, DECC's National Energy Efficiency Data-Framework (NEED) study of 4 million individual households revealed that average number of rooms, household income, tenure type and type of dwelling were the most important

\footnotetext{
${ }^{2}$ LSOAs are census output areas of 500-700 households and based loosely on homogenous tenure and house types. LSOA boundaries align to those of local authorities (ONS 2013).
}

factors influencing the level of consumption at the individual level (DECC 2011c). Added to this, the most common fuel for space heating in UK housing is natural gas, but 4.3 million homes (approximately $17 \%$ of the housing stock) are not connected to the gas grid (Boardman 2010). This has implications for understanding consumption of non-gas fuels in these properties, although at present the only reliable data is available for those houses with electric heating. These studies present a range of potential variables influencing energy demand independent on the energy efficiency of the housing stock. The challenge is to identify potential inefficiency in the housing stock (as well as overconsumption) after accounting for the variation in physical, social, economic and climatic factors.

The need for a benchmarking approach

Rather than using raw energy consumption figures, a better way to indicate the potential to reduce energy demand would be to use an appropriate benchmark figure against which the actual demand could be compared. Luque-Martinez and Muñoz (2005) describe benchmarking as a method of 'identifying, learning and implementing the most effective practises and capacities from other cities in order for one's own city to improve its actions' (p. 414). In their review of subnational energy policy in the UK, Keirstead and Schulz (2010) state

Ideally, one would like to be able to state with confidence that one city is 'better' than another owing to its policies, rather than simply benefitting from a benign climate, unique economic structure or other fortuitous circumstances (p. 4877).

Normalising energy consumption to take into consideration these 'fortuitous circumstances' would enable local authorities to benchmark energy consumption within their areas and monitor the success of energy efficiency reduction schemes in reducing energy consumption relative to this benchmarking figure. Keirstead (2013) provides a comprehensive review of benchmarking mechanisms that could be applied to measuring the energy efficiency of the housing stock at Local Authority level. Many of these techniques would require specialist computational inputs, such as the following: total factor productivity (TFP), where there is a need to apply an indicator of productivity so 
that forecasting mechanisms can be applied to historical data (Jamasb and Pollit 2000); data envelopment analysis (DEA), whereby computational analysis based on a number of factors unique to each area of study is required (Jamasb and Pollit 2000; Keirstead 2013) or frontier approaches that require large samples of bottom up data (Jamasb and Pollit 2000). The computational requirements for these benchmarks would likely deter Local authorities from developing energy efficiency monitoring strategies.

Alternative ways of identifying areas of inefficient housing would be to examine the energy efficiency measures installed in dwellings, for example as recorded in the Home Energy Efficiency Database (HEED) or energy performance certificates (EPC), which includes information on the physical characteristics of the houses. The problem is HEED only covers $50 \%$ of the housing stock at present and EPC data is only required for houses sold or rented since 2008 (Watts et al. 2011, DECC 2012). Importantly, EPCs are based on a prediction of likely energy demand, normalised to standard occupancy and so often reflect actual energy demand very poorly: the so-called performance-prediction gap. The use of EPCs and HEED also adds to the administrative burden of local authorities and to the contractor firms delivering energy efficiency schemes, because they require intensive data collection and analysis.

\section{Contribution of the research}

The aim of this paper is to demonstrate a new method for benchmarking domestic energy consumption that accounted for factors outside of the control of domestic energy policy tools, utilising widely available national energy statistics. The method should be designed in order to assist policymakers in identifying areas that may benefit from energy efficiency measures whilst removing the need to collect large databases of energy performance certificates and installed measures - meaning this information is available at low cost to local authorities. These benchmarks should normalise the data so that 'the direction and range of each metric is comparable' (Keirstead 2013, p. 576). To achieve this, the paper seeks to establish answers to the following questions:

- Independent of the energy efficiency performance of the housing stock, what are the driving factors that impact on energy consumption in the domestic sector within Local authority boundaries?
- How can the energy consumption occurring with local authority boundaries be assessed objectively given that the size of existing houses, the income of the occupants, the weather and level of gas grid connectivity is largely beyond local authority control?

- How do the benchmark results relate to areas of known energy efficiency in the housing stock?

The paper is structured as follows. Section 2 outlines the materials and methods used, introduces the datasets analysed and explains the methodological approach that produces energy consumption indices (ECI). Section 3 presents the results from the study and the validation of the ECIs. The implications of this research is discussed in section 4, before finally, section 5 examines the policy implications and next research steps.

\section{Method}

Secondary data to describe gas and electricity fuel consumption and the key explanatory variables were sourced, as shown in Table 1 . These data were readily available and had been used in previous UK Government research, most notably in the NEED report (DECC 2011c; 2013c). Statistical models were constructed to predict gas consumption, and to predict electricity consumption, from the explanatory variables. The fuel consumption data was then compared with these benchmarks to create ECIs. Attempts were made to verify the results, explore how they changed from year to year and rank the local authorities based on the performance of the housing within their boundaries. To demonstrate the method, all of the work described here was carried out for England only.

Fuel consumption data

Gas and electricity consumption data for 2010 were used as the dependent variables in the statistical modelling. They were obtained from the open access, sub-national, gas and electricity statistical releases published annually by DECC (2013d). These data are aggregated at the level of LSOAs, which are loosely based on homogenous tenure and house types (ONS 2013). There are 32,482 LSOAs in England each containing between 400 and 1200 homes, the average being between 500 and 700 homes (ONS 2013). As a result, rural LSOAs cover a much larger geographical area than urban LSOAs. 
Table 1 Data sources used in study

\begin{tabular}{|c|c|c|c|c|c|c|}
\hline Data source & Organisation & $\begin{array}{l}\text { Published variables } \\
\text { (year described) }\end{array}$ & Year & $\begin{array}{l}\text { Published Official } \\
\text { at LSOA statistics }\end{array}$ & $\begin{array}{l}\text { Frequency } \\
\text { of update }\end{array}$ & $\begin{array}{l}\text { Measured } \\
\text { or modelled }\end{array}$ \\
\hline \multirow[t]{6}{*}{$\operatorname{DECC}(2013 \mathrm{~d})$} & \multirow[t]{6}{*}{ DECC } & Total electricity consumption & \multirow[t]{6}{*}{2010} & & Annual & Measured \\
\hline & & Total gas consumption & & & Annual & Measured \\
\hline & & Per meter electricity consumption & & & Annual & Measured \\
\hline & & Per meter gas consumption & & & Annual & Measured \\
\hline & & Number of gas meters & & & Annual & Measured \\
\hline & & Number of electricity meters & & & Annual & Measured \\
\hline $\begin{array}{l}\text { Census Dissemination } \\
\text { Unit (2013a) }\end{array}$ & Experian Mosaic & Median household income & 2010 & & Annual & Modelled \\
\hline \multirow{8}{*}{$\begin{array}{l}\text { Census Dissemination } \\
\text { Unit }(2013 b)\end{array}$} & \multirow[t]{8}{*}{2001 Census } & Average number of rooms per house & \multirow[t]{8}{*}{2001} & & 10 years & Measured \\
\hline & & Percentage of owner occupiers & & & 10 years & Measured \\
\hline & & Percentage of social renting households & & & 10 years & Measured \\
\hline & & Percentage of private renting households & & & 10 years & Measured \\
\hline & & Percentage of detached houses & & & 10 years & Measured \\
\hline & & Percentage of semidetached houses & & & 10 years & Measured \\
\hline & & Percentage of terraced houses & & & 10 years & Measured \\
\hline & & Percentage of flats & & & 10 years & Measured \\
\hline MET Office (2013) & MET Office & Heating degree days 1988-2006 & 2006 & & Constant & Modelled \\
\hline
\end{tabular}

The gas consumption data were supplied to DECC by Xoserve, a private company responsible for collating gas consumption in the UK national gas network (DECC 2013b). Electricity consumption data were supplied to DECC directly from energy suppliers. The consumption figures are based on the metered data (or estimated consumption where meter readings are unavailable) used for customer billing. To date, the sub-national domestic gas and electricity consumption data have been published at LSOA level for the years 2008-2011, with a commitment to annual releases following an 18-month lag (DECC 2013b). The work described in this paper was carried out before the release of the 2011 dataset.

For the year 2010, the mean domestic gas and electricity consumption was calculated for each LSOA from the total fuel demand and the number of meters for that fuel. Total electricity consumption was calculated by summing 'economy7' and 'ordinary' domestic data. ${ }^{3}$ The published LSOA gas consumption data are weather corrected to an average base year of a 17-year average for 1988-2004 to distinguish changes in gas consumption levels from annual variations in the weather (National Grid 2012; DECC

\footnotetext{
${ }^{3}$ Economy 7 is a two period tariff structure comprising premium cost daytime (7 a.m.-midnight) and lower-cost night-time (midnight-7 a.m.) electricity designed to encourage off-peak demand and support the use of night-time storage heating.
}

2013b). This influenced the choice of weather variable as discussed in 'Explanatory variables'. LSOAs with no connection to the national gas grid were not included in the gas model and were not recorded in the DECC gas consumption statistics. In the published LSOA gas consumption data, those LSOAs with fewer than 6 (but more than 1) gas meters are merged with neighbouring LSOAs to avoid disclosure of the demand for individual homes (DECC 2013b). In these cases, the average gas consumption was assigned to all of the merged LSOAs. It is acknowledged that this presents a challenge to local authorities with 'merged' LSOAs within their boundaries but this affects $0.3 \%$ of total domestic gas consumption in England and covered $1.7 \%$ of LSOAs.

Descriptive statistics were calculated to examine how domestic energy consumption varies across England at LSOA level. Skew and kurtosis values were calculated and examined, and square root transformations were performed to bring the distributions of these consumption figures closer to a normal distribution.

\section{Explanatory variables}

Explanatory variables were sourced to represent variations in house size, household income, external air temperatures and primary heating fuels (see Table 1). Data 
on the physical size of houses, even at LSOA level, were not readily available and so, in keeping with other studies (see Baker and Rylatt 2007, DECC 2013c), the average number of rooms per house from the 2001 Census was used to approximate house size. Although house type and tenure have been shown to be strongly correlated with the size of house (DECC 2013c), tenure and house types were included from the 2001 Census to confirm this. Whereas most variables are based on measurement, it should be noted that the Experian median household income data is modelled from household credit surveys.

The gas consumption statistics are weather corrected temporarily, using a 'composite weather variable' (CWV) accounting for temperature and wind speed to a 'base year' of a 17-year average of 1988-2004 to enable year-on-year comparisons of gas consumption independent of weather effects (DECC 2013b; National Grid 2012). However, this variable does not account for spatial variation in external air temperature for different LSOAs. Therefore, spatially weighted average annual heating degree days ${ }^{4}$ were calculated using GIS for each LSOA in England using data obtained from the MET Office's UKCP09 directive for the years 1988 to 2004 at $5 \times 5-\mathrm{km}$ grid squares (MET Office 2013) assigned to the relevant LSOAs sourced from the UK Borders facility at Edinburgh University (EDINA 2013). This time period matches the averaged year used for the weather correction of the gas consumption data (National Grid 2012; DECC 2013b).

\section{Statistical modelling}

Multiple linear regression was selected as the method most appropriate for evaluating long-term trends and benefits from simple inputs and outputs, where the dependent variable is related to various independent variables (Swan and Ugursal 2009, Ren et al. 2012; Aydin 2014) - as is the case in domestic gas and electricity consumption. Regression analysis is also held up as a suitable method for providing results in a format that are relatively simple to interpret for non-statistical

\footnotetext{
${ }^{4}$ Heating degree days are a function of the length of time the external air temperature is below a specified base temperature, and how far below the base temperature the air temperature is, giving a linear relationship between temperatures below the base temperature and heating energy demands of buildings. $15.5^{\circ} \mathrm{C}$ is the standard base temperature for domestic properties in the UK (Chartered Institute of Building Services Engineers 2006).
}

audiences, for example local authority officers (Bianco et al. 2009; Aranda et al. 2012). The use of a regression model is a compromise between the simplicity of the evaluation method and the accuracy of the result without requiring a significant amount of input data (Aranda et al. 2012). Tso and Yau's (2007) study comparing regression analysis, decision tree and neural networks for predicting electricity consumption found the difference in error between the three methods was minimal. Howard et al. (2012) use this as justification that multiple linear regression is a valid method for predicting electricity consumption of urban building energy use in New York City to determine costeffectiveness and policies for implementing energy efficiency and renewable energy programmes. Multiple linear regression therefore has the advantage of being simple to interpret and more widely-understood than more complex techniques such as decision tree and neural network methods.

Multiple linear regression models for gas consumption and electricity consumption were generated using the stepwise entry method in SPSS (IBM, Version 19). Each of the explanatory variables (average number of rooms, median household income, heating degree days and ratio of gas to electricity meters) had correlation coefficient of $|r|>0.25$ against the dependent variables and were therefore included. To ensure the independence assumption of multiple regression was not violated (see Moore et al. 2009), thus avoiding the problem of multicollinearity, the correlation between any two pairs of independent variables in the models was checked. When this exceeded $|r|>0.7$, the variable that produced the strongest change in $R^{2}$ in the stepwise entry process was retained. This process was repeated until no pairs of independent variables included in the model were correlated where $|r|>0.7$. Finally, to remove redundant variables in the model, only those variables that produced a change in $R^{2}$ of greater than 0.1 were included. This is because the number of LSOAs modelled exceeded $30,000(n=32,482)$ and therefore greatly increased the chances of spurious results being highlighted as statistically significant (Miles and Shevlin 2003).

The gas and electricity consumption predicted by the two models for each LSOA was used as the 'benchmark consumption' for that LSOA. ECIs were then calculated for every LSOA by dividing the recorded consumption figures (in the sub-national consumption data) by the benchmark consumption and then multiplying by 100 . This resulted in a scale where a score of 100 indicated 
that the average consumption for the relevant fuel in the LSOA was the same as the benchmark predicted by the model. This process is shown in Eq. 1. A score above 100 indicated that households in that LSOA were consuming more of that fuel, on average, than expected (potential inefficiency), whilst a score lower than 100 indicated less than expected (potential efficiency). The ECIs also indicate the scale of potential inefficiency. A gas ECI of 120 indicates the LSOA is consuming $20 \%$ more gas than would be expected.

Eq. 1. Calculation of the energy consumption index

$$
\mathrm{ECI}=\frac{\text { regression predicted consumption }}{\text { recorded consumption }} \times 100
$$

These ECIs provide local authorities with an evidence base for targeting their efforts in areas that will make the biggest impact in reducing domestic energy consumption. It is important to note that the model deals with aggregated data and therefore it is not possible to infer the relative energy consumption performances of individual households from the LSOA score (avoiding the ecological fallacy — see Gelman et al. 2001). The benchmarks and ECIs indicate to the model the relative energy consumption levels of householders on average within each LSOA. There is still a need for local knowledge and specific data to assess the specific individual energy uses at a household level. Nevertheless, the model provides indication for where local authority resources and efforts might be most appropriate targeted in order to encourage uptake of households to energy efficiency measures.

To demonstrate the practical applications for policymakers, maps of local authority areas with LSOA boundaries were overlaid with colour-coded results, in a GIS, so that their geographical location and spatial variation could be visualised as an aid to interpretation. Leicester and Milton Keynes were chosen as case studies for this visualisation. Leicester was chosen as it is a typical urban area, comprising houses constructed over more than 100 years, and was the focus of the $4 \mathrm{M}^{5}$ project that funded this study (Lomas et al.

\footnotetext{
$\overline{5}$ The 4M Project, Measurement, Modelling, Mapping and Management, 4M: An Evidence Based Methodology for Understanding and Shrinking the Urban Carbon Footprint was a research project funded by the Engineering and Physical Sciences Research Council under the Sustainable Urban Environments programme. The city of Leicester served as the case study region, incorporating carbon emissions from domestic and non-domestic buildings, as well as transport carbon emissions and carbon sequestration.
}

2010). Milton Keynes was expected to offer a contrasting result given its 'New Town' status as detailed in 'Case studies' and was used in previous academic studies (e.g. Summerfield et al. 2010a).

Case studies

Verifying the results was complicated by the absence of readily available data on the level of insulation in properties or the proliferation of electrical appliances. Therefore, case studies of areas known to contain houses of relatively energy efficient construction were used. This verification is based on the hypothesis that local authorities containing 'planned' settlements as part of the 1945-1975 'New Town Movement' (see Fothergill et al. 1983, Department of Communities and Local Government [DCLG] 2006) would have a more efficient housing stock and, therefore, a higher proportion of LSOAs with gas ECIs of less than 100. This is because these settlements contain less of the pre-1919 housing that is the least energy efficient. This was tested statistically using a $t$ test to compare New Town local authorities with what have been termed here 'PreExisting'. Whilst this may be adequate for gas consumption, there was not a similar way to test the model results for electricity consumption.

\section{Exploring changes over time}

ECIs can be calculated each year, using the most up-todate data that are available. In this way, the benchmarks will change each year to reflect the average performance of the housing stock, and the new ECIs will then demonstrate the relative performance of housing in each LSOA against these benchmarks. If the method is to be used for tracking the performance of areas of housing temporally, it is important that the model produces relatively stable benchmarks and ECIs and ensure that the results are not spurious for a single year. If the results indicated dramatic swings in the performance of areas, it would undermine any confidence in the method. ECIs were therefore calculated for an additional 2 years of data: 2008 and 2009. This was done by repeating the regression analysis for these years and updating the consumption data and median household income variable. As with the 2010 data, gas and electricity consumption were sourced from the sub-national energy statistics, and updated income data were sourced from Experian (as shown in Table 1). The ECIs for each of 
these 3 years were then compared to identify any LSOAs where large changes occurred.

Ranking local authorities

The 2010 ECI results were used to rank local authorities by the proportion of LSOAs with ECIs of greater than 100 . This is more appropriate than ranking local authorities by the mean ECI values, as the proportion ranking highlights those local authorities with the greatest number of LSOAs that would benefit from energy efficiency interventions. This enables local authorities to compare the energy efficiency of their housing stock against other councils and enable the central government to evaluate energy efficiency levels of local authorities across the country.

A map indicating the performance of local authorities in England was produced. The results for the Leicestershire/Derbyshire/Nottinghamshire areas of the East Midlands region of England were compared in this paper as they include the $4 \mathrm{M}$ city of Leicester and offer an interesting regional perspective by which comparisons could be made.

\section{Results}

Distribution of domestic fuel consumption in England

There is considerable variation in domestic per meter gas and electricity consumption across LSOAs in England, as shown in Figs. 1 and 2. This is particularly true for electricity consumption, which exhibits a long tail above the mean. The gas consumption figures show LSOAs with gas consumption of double the mean, whilst the tail of the electricity distribution extends to four times the mean. A square root transformation was applied to both gas and electricity consumption. Descriptive statistics are given in Table 2. The resulting distributions (from visual shape, skew values and kurtosis values) were a closer approximation to a normal distribution and therefore suitable for multiple linear regression.

Explanatory variables

The correlations between the dependent variables and the explanatory variables are shown in Table 3. This shows that the average number of rooms and the median household income have the strongest relationship with square root per meter gas consumption ( $r=0.727$ and $r=0.667$ respectively). These variables are also the strongest for square root electricity consumption $(r=0.596$ and $r=0.638$, respectively), whilst the ratio of gas to electricity meters variable also has a strong inverse relationship with per meter electricity consumption $(r=-0.628)$. These results are all expected given the reports in the academic literature and focus in policy documents. Incidentally, heating degree days has a relatively weak correlation with per meter gas consumption $(r=0.220)$. Whilst this lack of correlation with gas consumption may seem surprising, previous studies (e.g. Summerfield et al. (2010b) focused on changes to annual heating demands in a single location rather than on the regional variations explored here. The variables where explanatory variables had strong correlations $(|r|>0.7)$ with each other are shown in bold and highlight the correlation between average number of rooms with percentage of owner occupiers $(r=0.740)$, percentage of detached houses $(r=0.755)$ and percentage of flats $(r=-0.716)$. Average number of rooms was included in the regression analysis as it has the strongest relationship with both fuel types. These other variables were not included in the study.

Building models, benchmarks and consumption indices

The three input variables to the gas model-average number of rooms, median household income, heating degree days - account for $65.3 \%$ of the variation in square root per meter domestic gas consumption $\left(R^{2}=0.653\right.$, Table 4$)$. This result is statistically significant at the 0.05 level $\left(F_{3,31,956}=19,844, p<0.001\right)$. The model's residual plot against the predicted values was checked for evidence of heteroscedasticity. This plot showed a random scatter of residuals around the $y=0$ line. The model's form is shown in Eq. 2 .

Eq. 2. Per meter gas consumption model

$\mathrm{BMG}=(-25.53+9.88 \mathrm{ANR}+0.63 \mathrm{MHI}+16.36 \mathrm{HDD})^{2}$

Where $\mathrm{BMG}=$ benchmark gas consumption, $\mathrm{ANR}=$ average number of rooms, $\mathrm{MHI}=$ median annual household income ( $£$ 000) and HDD = heating degree days (1000's of ${ }^{\circ} \mathrm{C}$ days). 
Fig. 1 Distribution of untransformed per meter gas consumption

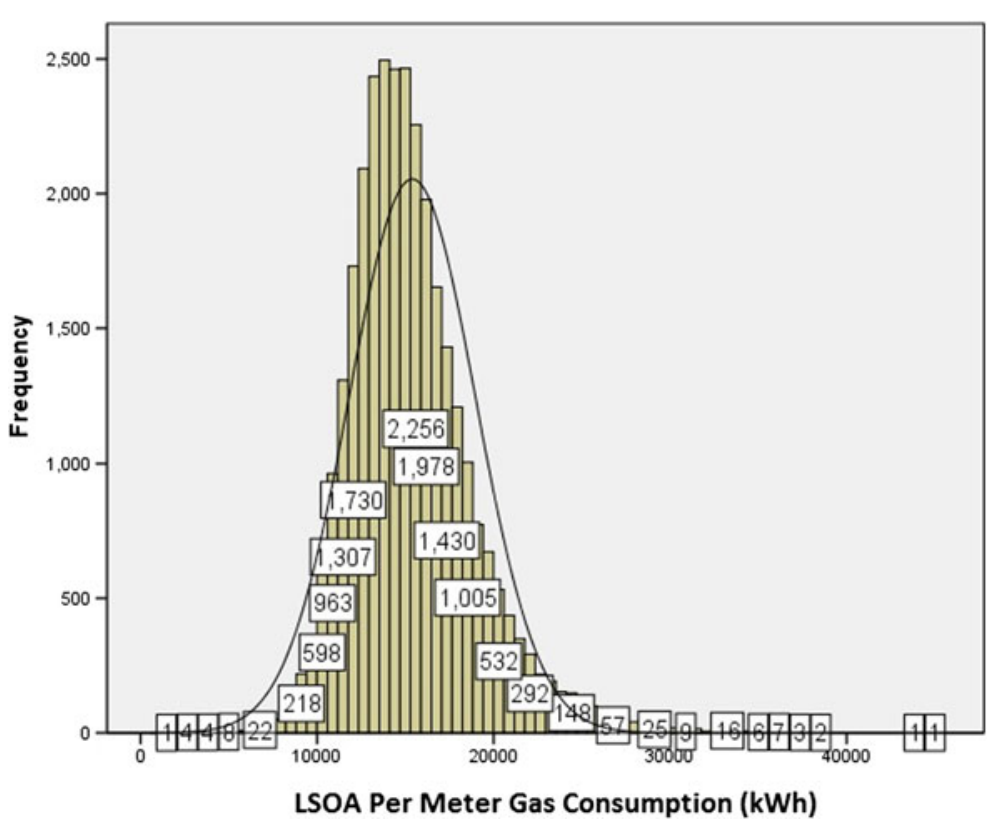

Eq. 3. Per meter electricity consumption model

$\mathrm{BME}=(51.47+3.86 \mathrm{ANR}-15.34 \mathrm{RGE}+0.22 \mathrm{MHI})^{2}$

Where $\mathrm{BME}=$ benchmark electricity consumption, $\mathrm{ANR}=$ average number of rooms, $\mathrm{RGE}=$ ratio of gas to electricity meters and $\mathrm{MHI}=$ median household income ( $£$ 000).
Fig. 2 Distribution of untransformed per meter electricity consumption

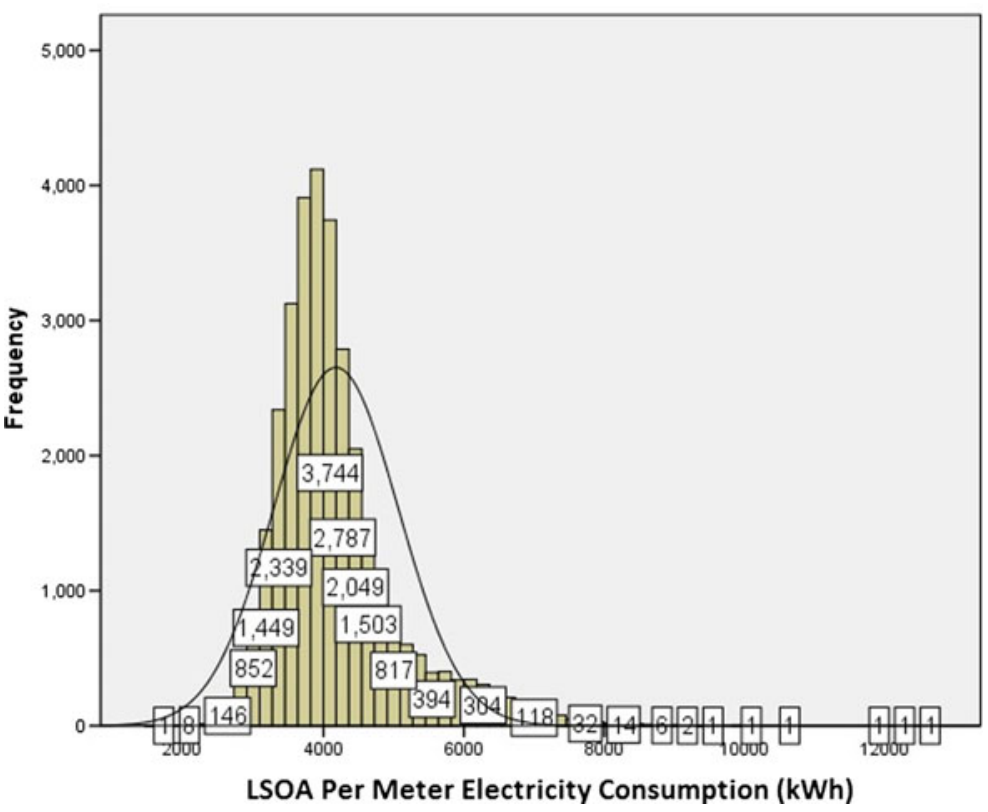


Table 2 Descriptive Statistics of Gas and Electricity Consumption Statistics

\begin{tabular}{ccccccc}
\hline & & Mean & Median & $\begin{array}{c}\text { Standard } \\
\text { deviation }\end{array}$ & Skew & Kurtosis \\
\hline \multirow{2}{*}{ Gas } & Untransformed $(\mathrm{kWh})$ & 15,732 & 14,875 & 3581 & 1.168 & 3.196 \\
& Transformed $(\sqrt{ } \mathrm{kWh})$ & 123 & 122 & 13.9 & 0.60 & 1.80 \\
\multirow{5}{*}{ Electricity } & Untransformed & 4140 & 3969 & 851 & 1.71 & 5.13 \\
& Transformed $(\sqrt{ } \mathrm{kWh})$ & 64 & 63 & 6.2 & 1.23 & 2.77 \\
\hline
\end{tabular}

Graphical displays of predicted gas against actual gas consumption are shown in Fig. 3, and the corresponding graph for electricity consumption is given in Fig. 4. In both cases, the line indicates where actual consumption is equal to the benchmark. LSOAs above the line are consuming more than the benchmark, and those below less.

ECIs for each LSOA were calculated from the ratio of actual consumption to the calculated benchmarks. As an example, the geographical and spatial variation in gas ECIs for the Leicester and Milton Keynes local authorities are shown in Fig. 5. The darker areas are the LSOAs with the most potential to benefit from energy efficiency improvements, as these areas are those with recorded consumption levels in excess of the benchmarked level. In Leicester, there is a concentration of LSOAs with high ECIs around the city centre. These areas contain some of the oldest properties in the city. Clustering of dwellings of high energy consumption is hypothesised by Tian et al. (2014) and there is some evidence of this occurring here. Within this group are 'green' LSOAs, given by lighter shading, which may indicate a greater number of energy efficient properties as their consumption levels are lower than the national average predicted by the benchmark, indicated in Figs. 3 and 4 by lighter shading. For Milton Keynes, a far higher proportion of LSOAs have ECIs below 100, though with notable exceptions of areas of the original settlements that existed prior to the development of the planned settlement. What these results highlight are the differences between local authorities: Leicester is primarily an (ex-)industrial city; Milton Keynes, a largely post-1960 planned urban area and therefore expected to have housing stock that is more thermally efficient.

Plausibility studies

It was not possible to validate the model comprehensively. However, a number of checks were carried out.
The first plausibility test involves comparing local authorities with new or expanded towns (termed 'New Towns') against local authorities without these developments (termed 'Pre-Existing'). Local authorities were classified as being 'New Town' if they contained planned settlements listed in DCLGs (2006) 'Lessons Learned from New Towns'. There are 51 local authorities with New Town developments, and 302'preexisting'. New Town local authorities had an average of $36 \%$ of LSOAs with a gas ECI $>100$, whilst preexisting local authorities had an average of $47 \%$. Running a $t$ test at 0.05 level $\left(t_{352}=4.74, p<0.001\right.$, Table 6) shows that there is a statistically significant difference in the proportion of ECIs above 100 between New Towns and Pre-Existing authorities This strongly indicates that new towns have more efficient housing stocks and gives confidence in the results of the model.

Repeating this analysis for electricity consumption shows that the average proportion of LSOAs with higher than expected consumption is $47 \%$ for New Town local authorities, and the corresponding figure is $48 \%$ for the Pre-Existing local authorities. This difference is not statistically significant at the 0.05 level $\left(t_{352}=0.349, p=0.73\right.$, Table 7$)$. This is an expected finding as the thermal efficiency of the housing stock is not likely to impact on average electricity consumption. Policy options will clearly be different when reducing electricity consumption and verification of this model is problematic.

\section{Exploring the changes in the ECIs temporally}

The over-time analysis showed that ECIs for both gas and electricity consumption between 2008 and 2010 were relatively stable. Table 8 shows that the mean change is approximately zero and over $99 \%$ of LSOAs change by less than 20 points between years for both gas and electricity consumption. There are a small number of LSOAs for which ECIs change dramatically. Examination of the results for these LSOAs 


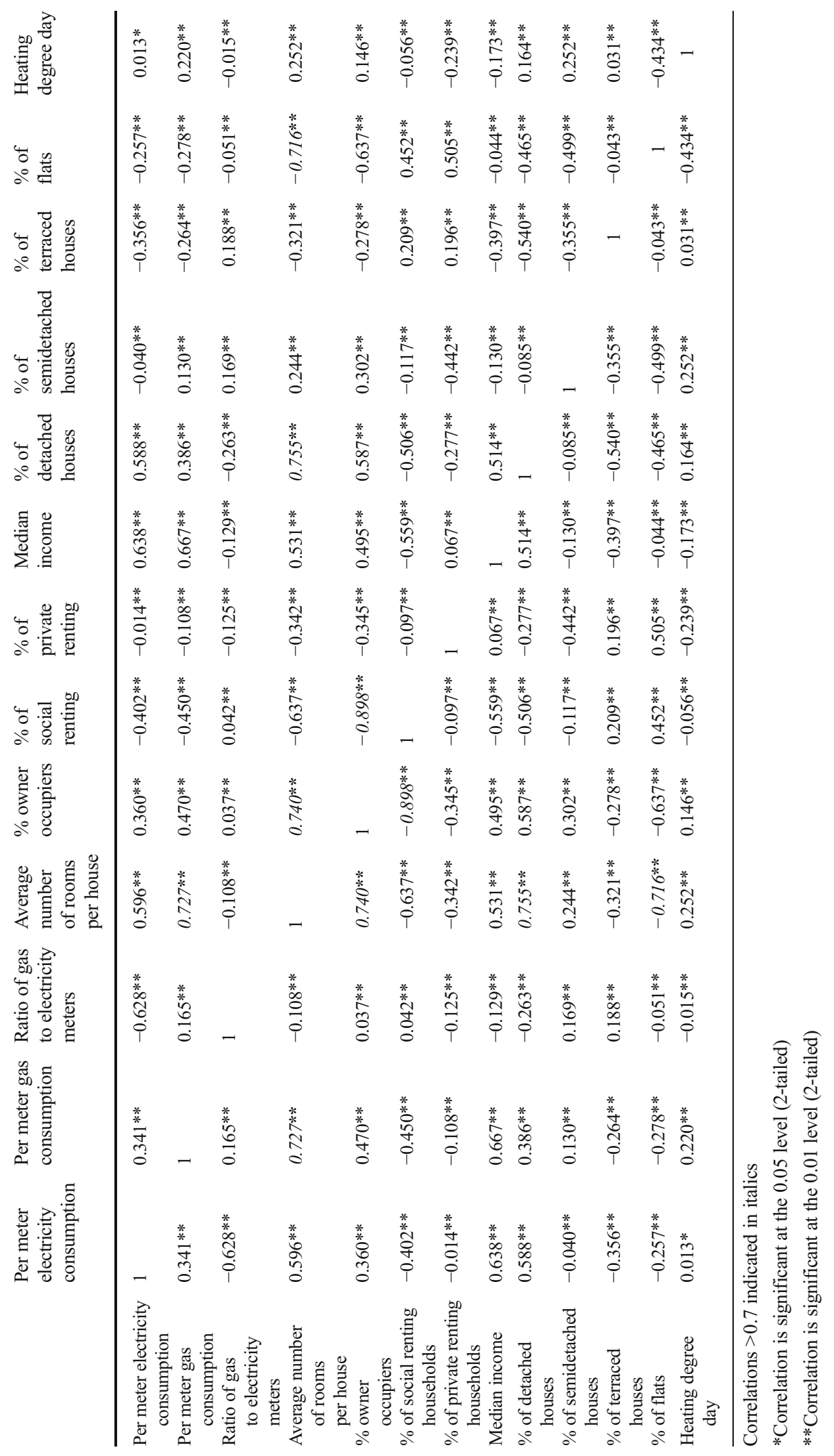


Table 4 Multiple regression model for square root per meter gas consumption

\begin{tabular}{|c|c|c|c|c|c|c|c|c|c|c|c|}
\hline \multirow[b]{2}{*}{$\begin{array}{l}\text { Independent } \\
\text { variable }\end{array}$} & \multirow[b]{2}{*}{$\begin{array}{l}\text { Change } \\
\text { in } R^{2}\end{array}$} & \multirow[b]{2}{*}{$\begin{array}{l}\text { Adjusted } \\
R^{2}\end{array}$} & \multirow[b]{2}{*}{$p$} & \multicolumn{3}{|l|}{ Coefficients } & \multicolumn{2}{|c|}{$\begin{array}{l}\text { Variable } \\
\text { significance test }\end{array}$} & \multicolumn{3}{|c|}{ Model statistics } \\
\hline & & & & Unstandardised & $\begin{array}{l}\text { Standard } \\
\text { error }\end{array}$ & Standardised & $t$ value & $p$ & $\begin{array}{l}\text { Model } \\
R^{2}\end{array}$ & $\begin{array}{l}F \\
\text {-statistic }\end{array}$ & $p$ \\
\hline Constant & - & - & - & -25.53 & 0.59 & - & 44 & $<0.001$ & 0.653 & 19,844 & $<0.001$ \\
\hline $\begin{array}{l}\text { Average number } \\
\text { of rooms }\end{array}$ & 0.534 & 0.534 & $<0.000$ & 9.88 & 0.09 & 0.45 & 106 & $<0.001$ & & & \\
\hline $\begin{array}{l}\text { Median household } \\
\text { income }(£ 000)\end{array}$ & 0.079 & 0.613 & $<0.000$ & 0.63 & 0.01 & 0.43 & 102 & $<0.001$ & & & \\
\hline $\begin{array}{l}\text { Heating degree day } \\
\quad(1000 \text { K-days })\end{array}$ & 0.040 & 0.653 & $<0.000$ & 16.36 & 0.27 & 0.22 & 60 & $<0.001$ & & & \\
\hline
\end{tabular}

highlight that these fluctuations were due to changes in the underlying data. For example, the gas ECI changes by over 40 points in 2009 for 13 LSOAs because the number of gas meters recorded in the 2009 dataset is significantly different to those recorded for 2008 and 2010. Other reasons for large changes in the energy consumption index included changes in the number of gas and electricity meters, which may be due to housing developments, and significant increases in income (particularly in four London LSOAs between 2009 and 2010). Whilst the number of LSOAs experiencing large swings in ECIs is small, it is important for users of these data to be aware of why any large changes arise. This could be realised by supplying the underlying data alongside the ECIs.

Ranking of local authorities

Local authorities in the Leicestershire/Derbyshire/ Nottinghamshire areas of the East Midlands region of England were ranked as shown in Fig. 6. The best performing local authority had only $30 \%$ of LSOAs with ECIs above 100, whilst the worst performing had over $80 \%$. From the map of the performance of local authorities in England it can be seen that there is a pattern towards urban areas having higher proportions of local authorities with gas consumption indices above 100 (Fig. 7). This fits with the analysis comparing Leicester and Milton Keynes and the trend of former industrial cities having a higher percentage of inefficient housing stock than the rest of England.

\section{Discussion}

The UK Government recognises the potential for domestic energy demand to play an important role in reducing $\mathrm{CO}_{2}$ emissions. The publication of domestic gas and electricity demand statistics at LSOA level are intended

Table 5 Multiple regression model for square root per meter electricity consumption

\begin{tabular}{|c|c|c|c|c|c|c|c|c|c|c|c|}
\hline \multirow[b]{2}{*}{$\begin{array}{l}\text { Independent } \\
\text { variable }\end{array}$} & \multirow[b]{2}{*}{$\begin{array}{l}\text { Change } \\
\text { in } R^{2}\end{array}$} & \multirow[b]{2}{*}{$\begin{array}{l}\text { Adjusted } \\
R^{2}\end{array}$} & \multirow[b]{2}{*}{$p$} & \multicolumn{3}{|l|}{ Coefficients } & \multicolumn{2}{|c|}{$\begin{array}{l}\text { Variable } \\
\text { significance test }\end{array}$} & \multicolumn{3}{|c|}{ Model statistics } \\
\hline & & & & Unstandardised & $\begin{array}{l}\text { Standard } \\
\text { error }\end{array}$ & Standardised & $t$ value & $p$ & $\begin{array}{l}\text { Model } \\
R^{2}\end{array}$ & $\begin{array}{l}F \\
\text {-statistic }\end{array}$ & $p$ \\
\hline Constant & - & - & - & 51.47 & 0.18 & - & 285 & $<0.001$ & 0.731 & 26,724 & $<0.001$ \\
\hline $\begin{array}{l}\text { Average number } \\
\text { of rooms }\end{array}$ & 0.382 & 0.382 & $<0.000$ & 3.86 & 0.03 & 0.39 & 113 & $<0.001$ & & & \\
\hline $\begin{array}{l}\text { Ratio of gas to } \\
\text { electricity meters }\end{array}$ & 0.276 & 0.658 & $<0.000$ & -15.34 & 0.09 & -0.50 & -172 & $<0.001$ & & & \\
\hline $\begin{array}{l}\text { Median household } \\
\text { income }(£ 000)\end{array}$ & 0.073 & 0.731 & $<0.000$ & 0.22 & 0.00 & 0.32 & 94 & $<0.001$ & & & \\
\hline
\end{tabular}


Fig. 3 Plot of predicted values against recorded square root per meter gas consumption

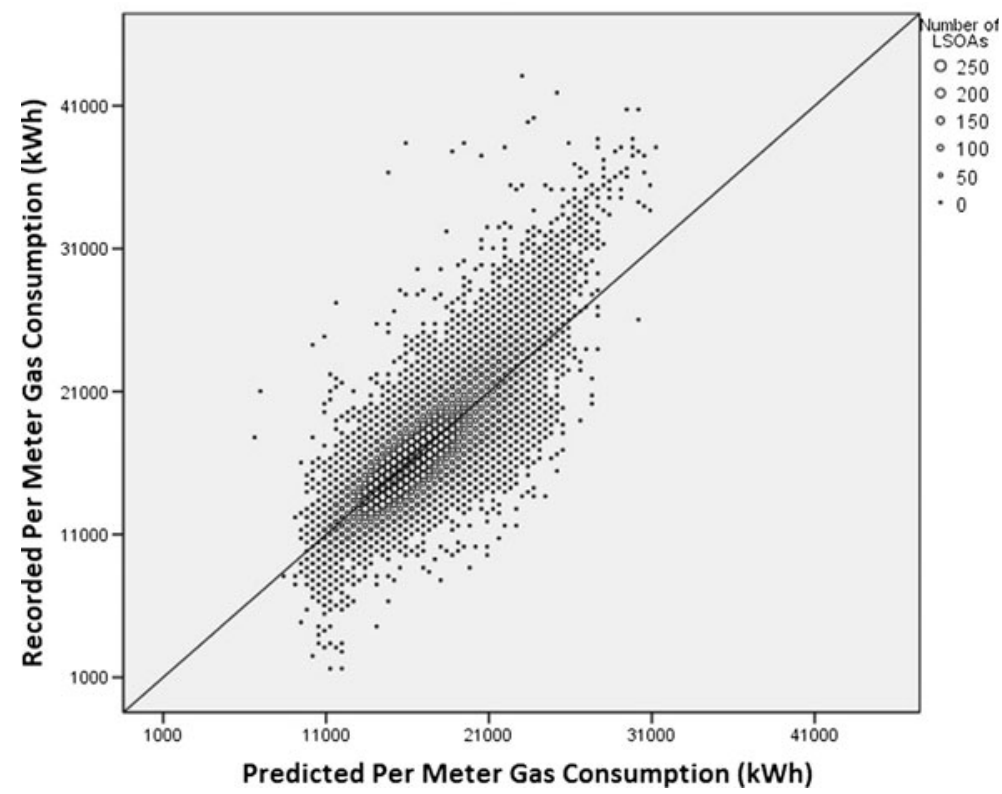

to provide an evidence base for targeting areas of housing that offer the biggest opportunity for demand reduction. But high energy demand does not necessarily mean that there is high potential for energy demand reduction.

The aim of this paper was to demonstrate a new method for benchmarking domestic energy demand that accounted for factors outside of the control of domestic energy policy tools, such as the Green Deal. This was achieved using a simple and easy to understand statistical model with readily available and regularly updated data. The relative performance of an area, compared with its benchmark, offers a method to assess the housing stock and to target areas for intervention. It also enables the relative performance of the stock to be monitored and the effectiveness of policy interventions to be assessed, by comparing annual results.
Fig. 4 Plot of predicted values against recorded square root per meter electricity consumption

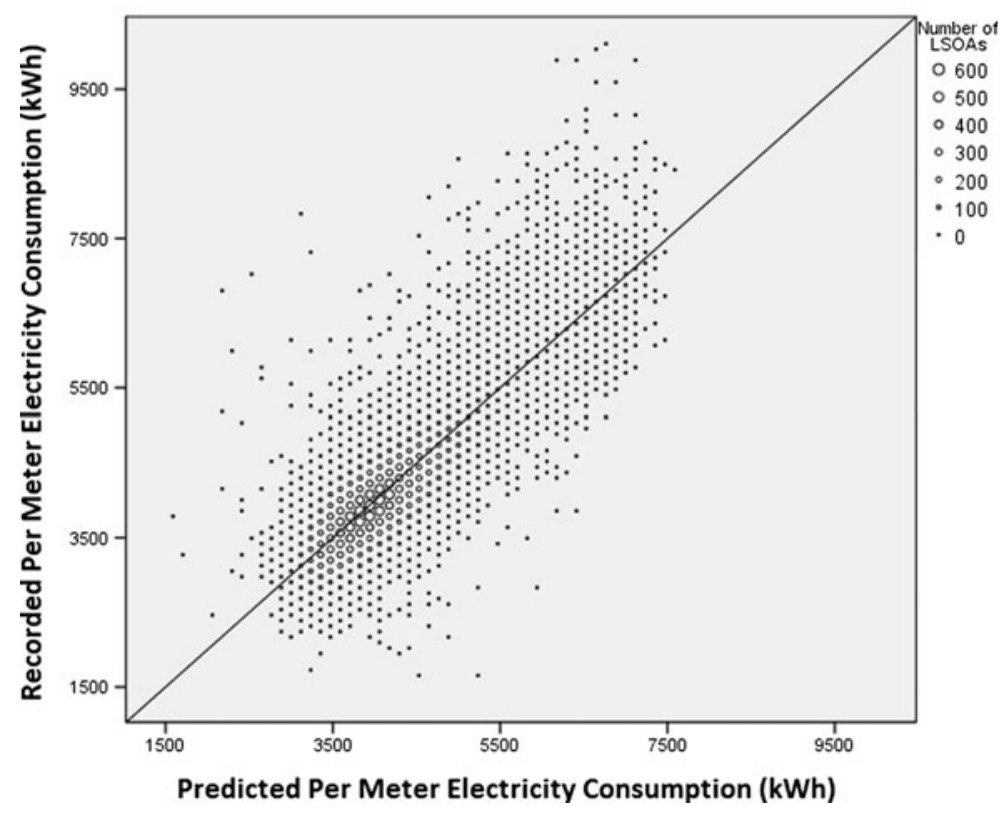




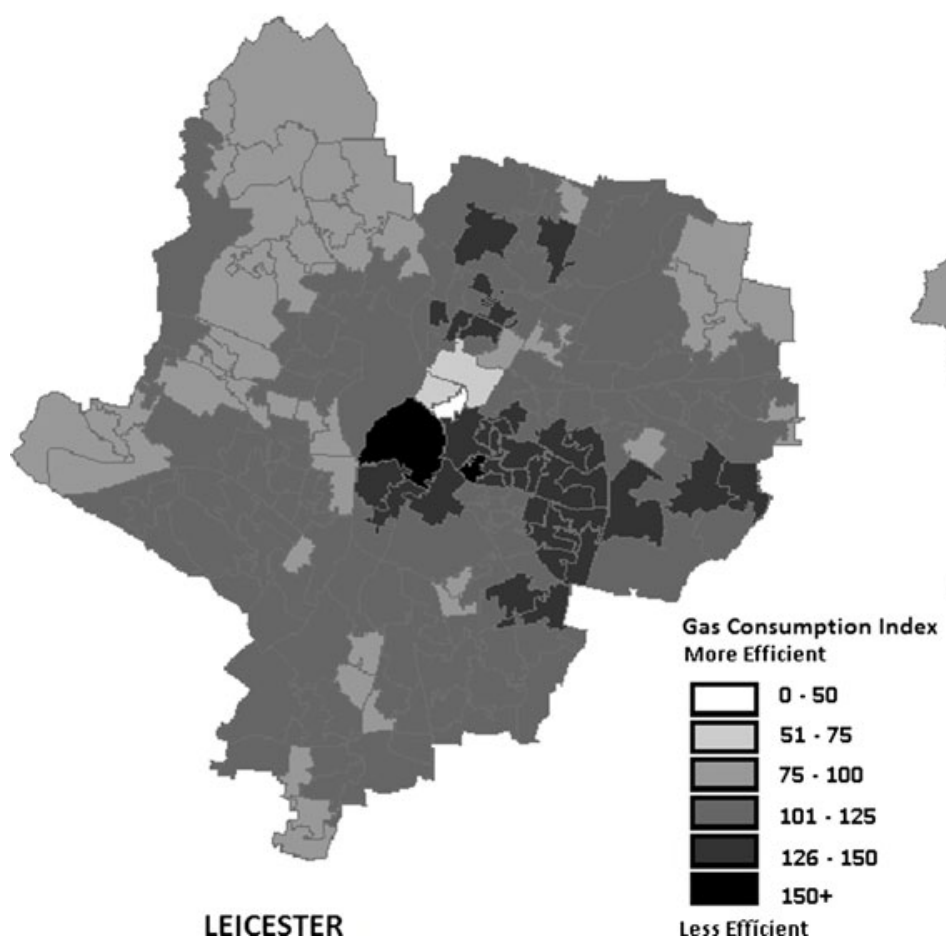

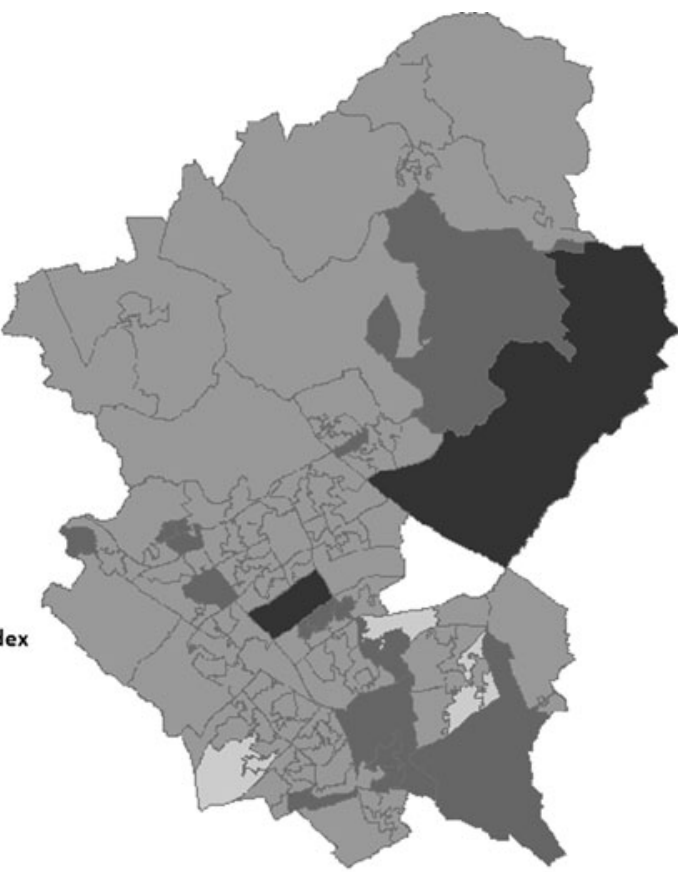

MILTON KEYNES

Fig. 5 Gas consumption indices for Leicester and Milton Keynes local authorities

The method

The approach used here to rating the LSOAs is not without precedent. In fact, it is similar in principle to the methods used in the UK, and elsewhere in Europe, to produce the operational rating (OR) of large public buildings. In both systems: the benchmark is based on actual measured energy use with fossil fuels and electricity considered separately; the benchmark is the average consumption for all buildings of the same type; the effects on energy demand of 'external factors' such as the local weather (expressed as heating degree-days), size of building and occupancy are accounted for and the performance of the actual building is compared to the benchmark and represented on a scale from 0 (excellent performance) upwards, with 100 being the benchmark value. Nonetheless, there are some differences: in the present method, there is just one building type, a home, whereas non-domestic buildings are divided into 29 types (schools, offices, small retail, etc.); here, the average number of rooms is a proxy for size, ORs are based on energy demand normalised by floor area $\left(\mathrm{kWh} / \mathrm{m}^{2}\right)$ and here, the occupancy factors is encapsulated as median annual household income, ORs account for the daily duration of building use.

A further difference is that in the present method ECIs are produced separately for gas and electricity. This makes sense for UK homes because gas is used primarily for space and hot water heating, whereas electricity is used for lighting, appliances, etc. Energy efficiency measures that target gas use are quite different from those that target electricity use. The former being primarily, insulation, draught proofing, more efficient heating equipment and better heating controls, whereas
Table 6 Comparing the proportion of LSOAs with higher than expected gas consumption in new/expanded towns and preexisting settlements

\begin{tabular}{lcccc}
\hline & $\begin{array}{l}\text { Number of local } \\
\text { authorities }\end{array}$ & $\begin{array}{l}\text { Mean proportion of } \\
\text { LSOAs where CI > 100 }\end{array}$ & $\begin{array}{l}\text { Standard } \\
\text { deviation }\end{array}$ & Interquartile range \\
\hline Pre-existing & 302 & $46.81 \%$ & $22.63 \%$ & $39 \%(26.5-65.5)$ \\
New/expanded & 51 & $32.61 \%$ & $19.26 \%$ & $29 \%(14.6-43.6)$ \\
\hline
\end{tabular}


Table 7 Comparing the proportion of LSOAs with higher than expected electricity consumption in new/expanded towns and preexisting settlements

\begin{tabular}{lcccc}
\hline & $\begin{array}{l}\text { Number of } \\
\text { local authorities }\end{array}$ & $\begin{array}{l}\text { Mean proportion of } \\
\text { LSOAs where CI }>100\end{array}$ & $\begin{array}{l}\text { Standard } \\
\text { deviation }\end{array}$ & Interquartile range \\
\hline Pre-existing & 302 & $48.13 \%$ & $20.37 \%$ & $29 \%(35.5-64.5)$ \\
New/expanded & 51 & $47.17 \%$ & $17.77 \%$ & $20 \%(39-59)$ \\
\hline
\end{tabular}

the latter might entail the purchase of more efficient white goods or behaviour changes (turning off lights, using a cooler wash) encouraged by information campaigns. In non-domestic buildings, the heating and cooling systems often use both fossil fuel (for heating) and electricity (for fans, pumps and chillers).

Finally, it is worth noting that the OR is based on the carbon dioxide released through the use of the fossil fuel and electricity (standard carbon intensity $\left(\mathrm{kgCO}_{2} / \mathrm{kWh}\right)$ values are used). It would be quite straight forward to combine the ECIs for gas and electricity, using standard carbon intensity values, to derive a single measure (although, as just noted, this would lose valuable energy efficiency targeting information). Using a $\mathrm{CO}_{2}$ measure would though be valuable if LSOAs (or local authorities) had extensive deployment of house-integrated or community renewable energy schemes that resulted in locally lower carbon intensity figures. But there would still be merit in separately reporting the $\mathrm{CO}_{2}$ originating from fossil fuels and electricity use. It is important to note that these models are designed to be easy to understand and interpret. The aim of the study is not to model the predicted energy consumption for specific households, but to provide metrics that identify areas with potential for undergoing energy efficiency interventions. This method not only would more reliably identify and define opportunities for intervention but also to learn from their own actions and the actions of other local authorities (Bale et al. 2012; Keirstead 2013).

Gas consumption

The modelled benchmark for gas consumption accounted for $65 \%$ of the variation in gas demand across English LSOAs by considering the average number of rooms (2001 Census), the median household income (Experian Mosaic) and the average annual heating degree days (MET Office). The influence of house size, income and the ambient temperature is supported by studies in the literature. It is assumed that the remaining variation is due to the thermal performance of the houses, the efficiency of their heating systems and the behaviour of the occupants. In this way, LSOAs with recorded gas consumption that is higher than the benchmark calculated by the model are assumed to have a significant number of households that would benefit from refurbishment. This could also be applied to behavioural strategies such as turning down the thermostat by $1{ }^{\circ} \mathrm{C}$ depending on the nature of the housing stock in these LSOAs. The calculation of heating degree days for each LSOA was the most complicated part of the modelling process and required a competent GIS user. However, this derived degree day data can be used for subsequent years' analysis as the gas consumption data
Table 8 Number and percentage of LSOAs by change in absolute values of consumption indices

\begin{tabular}{llllll}
\hline $\begin{array}{l}\text { Change in } \\
\text { consumption index }\end{array}$ & \multicolumn{2}{l}{ Gas consumption } & & \multicolumn{2}{l}{ Electricity consumption } \\
\cline { 2 - 3 } \cline { 5 - 6 } & $2008-2009$ & $2009-2010$ & & $2008-2009$ & $2009-2010$ \\
\hline$>|1|$ & $24,640(83 \%)$ & $25,198(79 \%)$ & & $26,168(80 \%)$ & $25,742(79 \%)$ \\
$>|5|$ & $5443(17 \%)$ & $6229(19 \%)$ & & $8284(26 \%)$ & $2950(9 \%)$ \\
$>|10|$ & $755(2 \%)$ & $849(3 \%)$ & & $1715(5 \%)$ & $1021(3 \%)$ \\
$>|20|$ & $115(0.3 \%)$ & $85(0.3 \%)$ & & $179(0.6 \%)$ & $92(0.3 \%)$ \\
$>|25|$ & $72(0.22 \%)$ & $60(0.19 \%)$ & & $95(0.29 \%)$ & $43(0.13 \%)$ \\
$>|50|$ & $20(0.06 \%)$ & $20(0.06 \%)$ & & $4(0.01 \%)$ & $2(0.02 \%)$ \\
$>|75|$ & $11(0.03 \%)$ & $10(0.03 \%)$ & & $1(0.003 \%)$ & $1(0.003 \%)$ \\
$>|100|$ & $2(0.006 \%)$ & $3(0.06)$ & & $1(0.003 \%)$ & $1(0.003 \%)$ \\
\hline
\end{tabular}




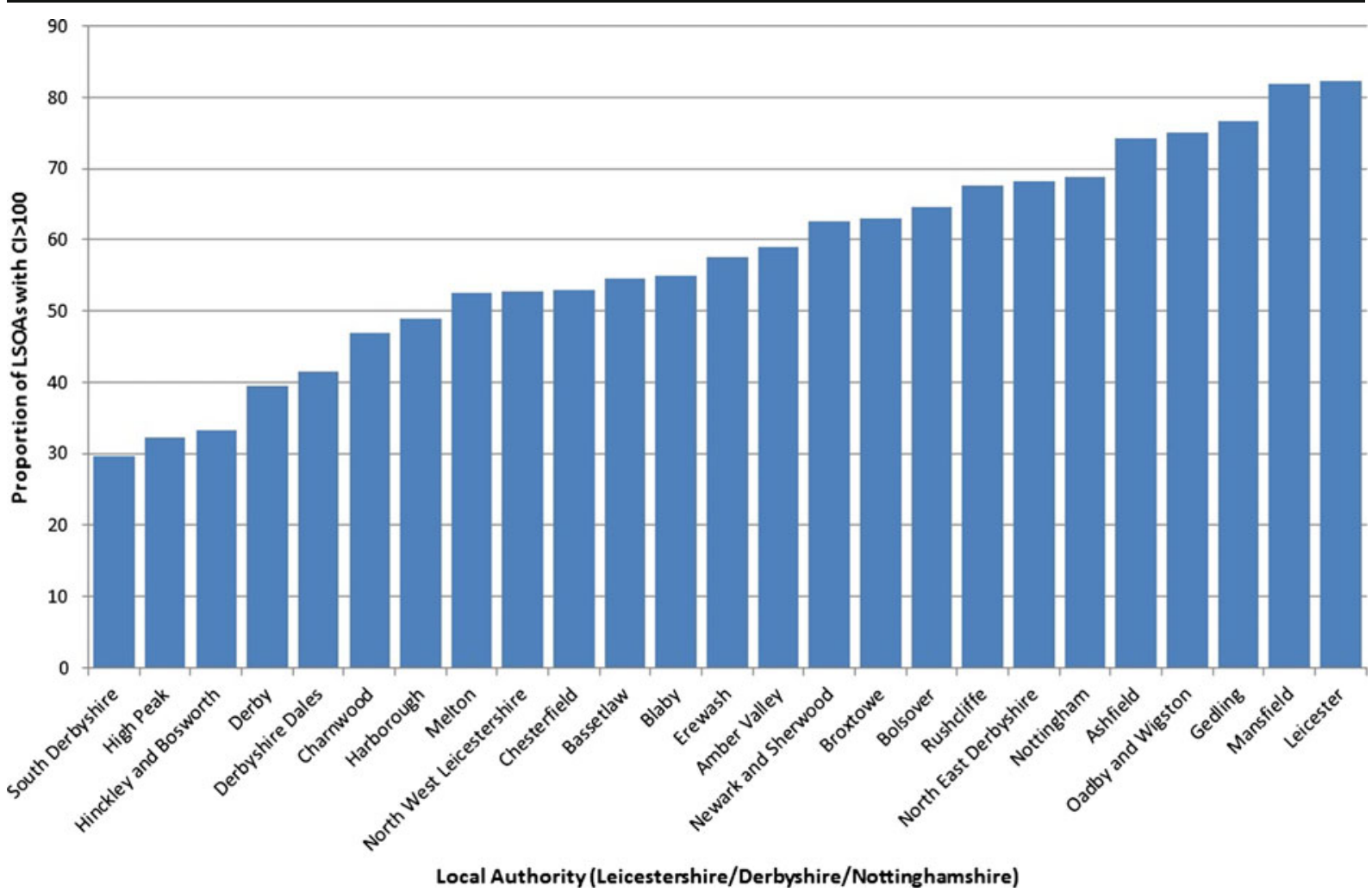

Fig. 6 Ranking local authorities in Leicestershire/Derbyshire/Nottinghamshire

are always corrected to the same 1998-2004 average base year.

ECIs were calculated from the ratio of actual consumption to the benchmark figure, with a result of 100 indicating they were equal. The results of the model showed that local authorities that contain post-1950 new town developments have statistically significant lower proportion of LSOAs with ECIs above 100. This finding is logical as, at present, there is a strong link between the age of houses and their thermal performances (see for example Boardman 2007, Dowson et al. 2012, DECC 2012, 2013b). It is expected that this link would weaken as areas of older housing are refurbished, and their thermal performance is improved. In this way, the method presented here is better for identifying inefficient houses than relying on the age of the housing stock. The ECIs are derived using an approach analogous to that used to produce the operational rating of non-domestic buildings, which is represented on a scale from 0 (energy efficient) through 100 (expected consumption for the building type) and upwards for less efficient buildings. The method has the potential to enable local authorities to isolate the inherent energy efficiency of housing stocks as influenced, for example by the extent of wall, roof and floor insulation or the heating system efficiency. It could also identify those households with higher than anticipated energy demands due to behavioural factors, for example higher internal temperatures (MacKay 2009; Leaman et al. 2010). The additional provisions of data at a smaller spatial scale would aid in developing both a detailed area-based assessment of potential energy efficiency in LSOAs and identifying individual properties within these areas.

The highest calculated ECIs might result from a combination of houses with poor thermal performance and occupants with high energy using behaviours. These are houses that have most to gain from refurbishment as their higher than average energy use will result in higher than average savings. The EPC data does not contain this combination of household energy use with house potential. The method presented here would also be less expensive to deliver than EPC data, especially if the benchmarks are generated centrally and published alongside the sub-national fuel consumption figures.

The method presented here will not be suitable for dealing with areas of housing that fall within the 
Fig. 7 Percentage of LSOAs within English local authorities with consumption indices $>100$

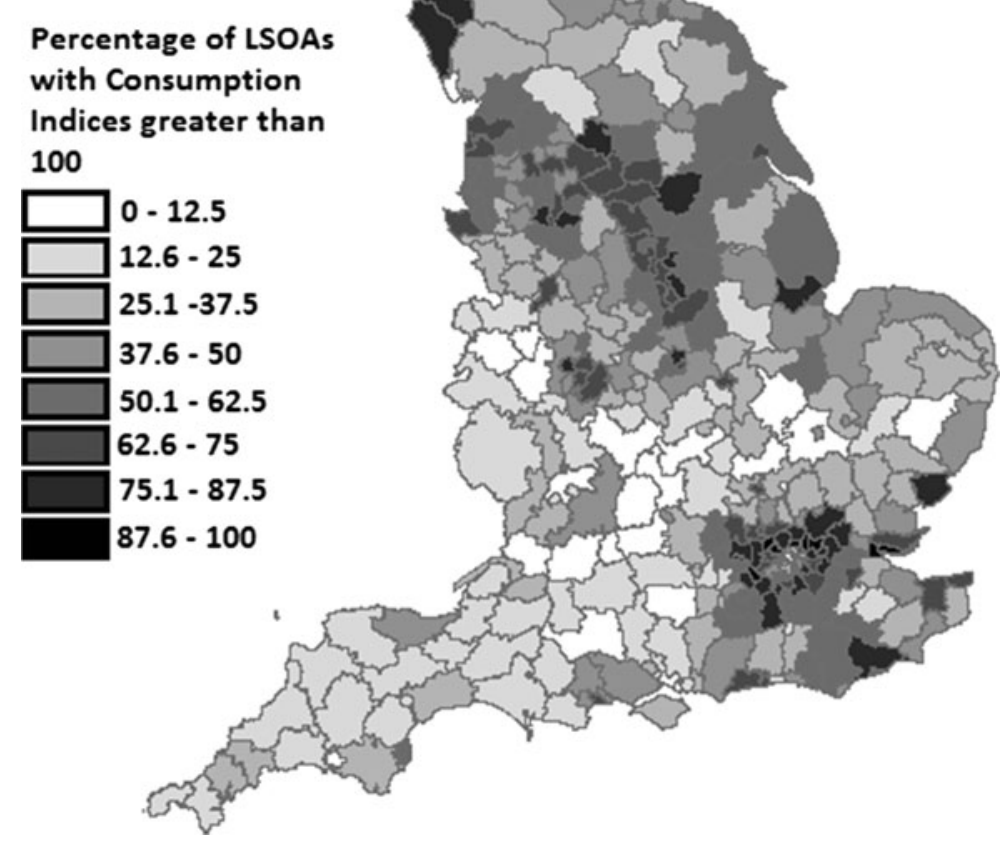

definition of fuel poverty. This is because the energy demand in these houses may be low, even though the housing is inefficient. Other methods exist for identifying fuel poverty (see Fahmy and Gordon 2007 for example). Also, households in fuel poverty are less suitable for refurbishment schemes like the Green Deal as the lower use of heating results in longer payback times, which was acknowledged from the ECO consultation. Another limitation of the method presented here is that areas of housing heated by fuels other than gas and electricity may not be well represented. The model presented here used 2001 Census data on the average number of rooms in each LSOA to help predict gas consumption for 2010. This could be problematic in areas with new housing developments, and it is recommended that 2011 Census data are used as they become available.

The use of these benchmarks is proposed as an improvement on using the raw domestic energy consumption data to monitor the performance of local authorities based on the energy demand in their area. This is because it removes the advantages of local authorities that benefit from what Keirstead and Schulz (2010) termed as 'a benign climate, unique economic structure or other fortuitous circumstances' (p. 4876). Constructing the ECIs at the LSOA level ensures that the results have practical applications for local authorities and their commercial partners in large-scale refurbishment schemes. This was highlighted as desirable in the Green Deal policy literature (DECC 2011b).

Electricity consumption

Considering the average number of rooms (2001 Census), the median household income (Experian Mosaic), and the ratio of gas to electricity meters (DECC) and the modelled benchmark for electricity consumption accounted for $73.1 \%$ of domestic electricity consumption across English LSOAs. The influence of house size, income and proportion of electric heating supports previous findings in the academic literature. However, unlike gas consumption, the factors accounting for the remaining variation are not as well understood. Despite the fact that the three variables included in the model were able to account for a greater proportion of the variation in consumption, the dependent 
variable was more heavily skewed and it was not possible to verify results in the same way as domestic gas consumption. The current Green Deal and ECO policies are unlikely to achieve large-scale reductions in electricity consumption (Dowson et al. 2012). This is because they focus on the condition of the housing stock and the thermal efficiency of the dwelling, whereas our model demonstrates the need to develop alternative approaches to reducing electricity consumption-something which is likely to be driven by household behaviour and the use of electricity-generating technologies, such as photovoltaic (PV) panels.

The results from this method could be used to monitor the impacts of localised policy trials such as energy efficiency educational campaigns, community-based action or the rollout of smart metering technologies that provide households with feedback on electricity demand - with more work clearly needed to explore the characteristics of households in areas with high electricity ECIs.

\section{Ranking}

The method presented in this paper, provides a way to rank local authorities, based on the proportion of their LSOAs that have ECIs above a chosen ECI threshold; illustrations are given herein for a threshold of 100. For the central government, this ranking offers a means to identify the local authorities that can make the most energy savings. This can also indicate to commercial companies, such as Green Deal providers, which local authorities offer the greatest opportunities from collaboration. It will also enable local authorities to compare their performance with neighbouring areas and can be used by councils to justify their focus on domestic energy consumption to their communities.

\section{Conclusions}

This paper offers a method to benchmark domestic gas and electricity consumption for small areas of housing (approximately 500-700 homes). Multiple linear regression models to generate benchmark domestic energy consumption show that three variables account for approximately $65 \%$ of the variation in per meter gas consumption and $73 \%$ of per meter electricity consumption. These three variables are drawn from the use of secondary data that described the variation in the size of housing, median household income, external air temperature and proportion of gas heating. This benchmarking process removes the effects of climate, infrastructure and wealth, enabling the energy efficiency of the housing stock in one area to be fairly compared with the stock in a different area. Comparing the actual gas and electricity demand of the houses in each LSOA with the modelled benchmark yields an ECI which clearly identifies those areas with the greatest potential for demand reduction. The model could be run centrally every year, new benchmarks published, progress monitored and the priority areas re-assessed. With this method, there will always be $50 \%$ of all the LSOAs with 'below average' ECI values and this ensures that local authorities which take no action will see their LSOAs energy performance decline temporally in relative terms.

The proposed gas ECIs offer advantages over energy demand, age of the housing or EPC data: areas of housing with high energy demand will not necessarily have a high potential for demand reduction; areas with older housing may already be refurbished and so offer no further potential; EPC data is incomplete and ignores the actual consumption of the households, although it should be noted that a supplementary Green Deal occupancy assessment does take the actual consumption into account if that information is available. Areas of housing with the highest gas ECIs represent relatively high energy-consuming households living in houses with relatively poor thermal performance. These are precisely the households that have most to gain from refurbishment and the Green Deal policy tool. Electricity ECIs offer an intriguing opportunity for furthering our understanding of electricity demand, but much more work is needed in this area. The authors argue that the current data provision is inadequate to assess the progress and success of area-based energy reduction strategies can be measured. The method presented in this paper provides improved data and a model to enable this in a way that does not mandate 'one size fits all' targets to all local authorities in the UK. The recommendation is that these benchmark and ECI data be published by DECC, as part of their ongoing commitment to providing data resources to local authorities, as well as being of interest to private Green Deal providers and energy efficiency companies, aiding the targeting of their marketing activities.

The main limitations of this model concerns the applicability towards identifying areas for fuel poverty 
interventions, particularly where households are consuming less than expected. Whilst policies to reduce heating energy consumption in the UK are relatively well advanced, further work is needed to develop policy to reduce electricity consumption. The electricity benchmarking method described in this paper could provide new insights into the consumption behaviours of households and offers a means of monitoring the impact of reduction schemes. Ultimately, it is hoped that this will help the UK Government to achieve its emissions reductions targets, and there is no reason that the method could not, in principle, be applied in other countries.

Acknowledgments The work was conducted as part of the 4M project, which was a consortium of four UK universities, funded by the Engineering and Physical Sciences Research Council under the Sustainable Urban Environments programme (grant reference EP/F007604/1). The university partners are assisted by an advisory panel drawn from UK central and local government and UK and overseas industry and academia.

The reported work flowed from a project focused on the East Midlands, engaging with the Housing Intelligence for East Midlands (Hi4em) organisation based at Derby City Council, and consulting with local authority representatives from Leicestershire, Derbyshire and Nottinghamshire. Their invaluable help, and especially that of David George (project manager, Hi4em) is gratefully acknowledged.

\section{References}

Aranda, A., Ferreira, G., Mainar-Toledo, M., Scarpellini, S., \& Sastresa, E. (2012). Multiple regression models to predict the annual energy consumption in the Spanish banking sector. Energy and Buildings, 49, 380-387.

Aydin, G. (2014). Modeling of energy consumption based on economic and demographic factors: the case of Turkey with projections. Renewable and Sustainable Energy Reviews, 35, 382-389.

Baker, K., \& Rylatt, M. (2007). Improving the prediction of UK domestic energy demand using annual consumption data. Applied Energy, 85, 475-482.

Bale, C., Foxon, T., Hannon, M., \& Gale, W. (2012). Strategic energy planning within local authorities in the UK: a study of the city of Leeds. Energy Policy, 48, 242-251.

Bianco, V., Manca, O., \& Nardini, S. (2009). Electricity consumption in Italy using linear regression models. Energy, 34, 1413-1421.

Boardman, B. (2007). Examining the carbon agenda via the $40 \%$ agenda. Building Research and Information, 35(4), 363-378.

Boardman, B. (2010). Fixing fuel poverty: Challenges and solutions. London: Earthscan.

Census Dissemination Unit (2013a). Experian data. http://cdu. mimas.ac.uk/experian/index.htm. Accessed 12 Jan 2014.
Census Dissemination Unit (2013b). 2001 Census. http://cdu. mimas.ac.uk/2001/index.htm. Accessed 12 Jan 2014.

Chartered Institute of Building Services Engineers (2006). Degree days: Theory and application. London: CIBSE.

Commission of the European Union (2010). DIRECTIVE 2010/31/EU OF THE EUROPEAN PARLIAMENT AND OF THE COUNCIL of 19 May 2010 on the energy performance of buildings (recast). http:/www.eceee.org/policyareas/buildings/EPBD_Recast/EPBD_recast_19May2010. pdf. Accessed June 2015.

DCLG (2006). Transferable lessons from the new towns. London: Crown Copyright, 06HC03919. http://www. futurecommunities.net/files/images/Transferable_lessons from_new_towns_0.pdf Accessed 28 May 2015

DECC (2011a). Green Deal summary proposals. London: Crown Copyright, 10D/996. https://www.gov.uk/government/ uploads/system/uploads/attachment_data/file/47978/1010green-deal-summary-proposals.pdf. Accessed 12 Dec 2014.

DECC (2011b). Extra help where it is needed: a new energy company obligation. London: Crown Copyright. https:// www.gov.uk/government/uploads/system/uploads/ attachment_data/file/48086/1732-extra-help-where-it-isneeded-a-new-energy-compan.pdf. Accessed 12 Mar 2015.

DECC (2011c). National energy efficiency data-framework: report on the development of the data-framework and initial analysis. London: Crown Copyright, URN 11D/703. http://www. cewales.org.uk/cew/wp-content/uploads/National-EnergyEfficiency-Data-Framework.pdf. Accessed 12 March 2015.

DECC (2012). Guidance to English energy conservation authorities issued pursuant to the Home Energy Conservation Act 1995. London: Crown Copyright, UD 12D/296. https:// www.gov.uk/government/uploads/system/uploads/ attachment_data/file/180786/Updated_version_of_HECA_ guidance_-_March_2013.pdf. Accessed 12 Dec 2014.

DECC (2013a). Fuel poverty: a framework for future action. London: Department of Energy and Climate Change. https://www.gov.uk/government/uploads/system/uploads/ attachment_data/file/211180/FuelPovFramework.pdf. Accessed 26 Feb 2015.

DECC (2013b). Sub-national consumption statistics: methodology and guidance booklet. London: Crown Copyright, 12D/ 473. http://www.decc.gov.uk/assets/decc/statistics/regional/ m1soa2008/1_20100325121429_e_@@_ mlsoallsoaguidance.pdf. Accessed 6 Jan 2014.

DECC (2013c). National energy efficiency data-framework: summary of analysis using the national energy efficiency dataframework. Part 1: domestic energy consumption. London: Crown Copyright, 13D/145. https://www.gov.uk/ government/uploads/system/uploads/attachment data/file/ 209089/National_Energy_Efficiency_Data-framework June_2013_Part_I.pdf. Accessed 14 Jan 2015.

DECC (2013d). Sub-national energy consumption statistics. London: Department of Energy and Climate Change. https://www.gov.uk/government/organisations/departmentof-energy-climate-change/series/sub-national-energyconsumption. Accessed 6 Jan 2015.

Dowson, M., Poole, A., Harrison, D., \& Susman, G. (2012). Domestic UK retrofit challenge: barriers, incentives and current performance leading into the Green Deal. Energy Policy, 50, 294-305. 
EDINA (2013). UK BORDERS Homepage [online] http://ukbsrvat.edina.ac.uk/ukborders/. Accessed 12 Dec 2013.

Fahmy, E., \& Gordon, D. (2007). Updating the fuel poverty indicator for England. Bristol: Centre for Sustainable Energy [online] http://www.fuelpovertyindicator.org.uk/ downloads/FPI_Final_report_launch_clean.pdf. Accessed 122014.

Firth, S., \& Lomas, K. (2009). Investigating $\mathrm{CO}_{2}$ emission reduction in existing urban housing using a community energy model. Building Simulation 2009, Proceedings of the 11th IBPSA Conference, Glasgow [online] http://www.ibpsa.org/ proceedings/BS2009/BS09_2098_2105.pdf. Accessed 12 Dec 2013.

Forthergill, S., Kitson, M., \& Monk, S. (1983). The impact of new and expanded town programmes on industrial location in Britain, 1960-1978. Regional Studies, 17(4), 251260.

Gelman, A., Park, D., Ansolabegere, S., Price, P., \& Minnite, L. (2001). Models, assumptions and model checking in ecological regressions. Journal of the Royal Statistical Society A, 164, 101-118.

Hamilton, I., Steadman, J., Bruhns, H., Summerfield, A., \& Lowe, R. (2013). Energy efficiency in the British housing stock: energy demand and the homes energy efficiency database. Energy Policy, 60, 462-480.

HM Government (2008). Climate Change Act Chapter 27. London: The Stationary Office [Online] http://www. Legislation.gov.uk/Ukpga/2008/27/Pdfs/ukpga_20080027_ en.pdf Accessed 11 Apr 2014.

HM Government (2011). Energy Act 2011: Chapter 6. London: The Stationary Office, [online] http://www.legislation.gov. uk/ukpga/2011/16/pdfs/ukpga_20110016_en.pdf Accessed 12 Dec 2013.

Howard, B., Parshall, L., Thompson, J., Hammer, S., Dickinson, J., \& Modi, V. (2012). Spatial distribution of urban building energy consumption by end use. Energy and Buildings, 45, 141-151.

IGEM (2011). Out in the Cold: IGEM inaugural report on fuel poverty institute of gas engineers and managers. Kegworth. [online] http://www.igem.org.uk/media/ 146497/IGEM-Fuel-Poverty-2011-web.pdf. Accessed 13 Dec 2013

Jamasb, T., \& Pollitt, M. (2000). Benchmarking and regulation: international electricity experience. Utilities Policy, 9(3), 107-130.

Kannan, R., \& Strachan, N. (2009). Modelling the UK residential energy sector under long-term decarbonisation scenarios: comparison between energy systems and sectoral modelling Approaches. Applied Energy, 86, 416-428.

Keirstead, J. (2013). Benchmarking urban energy efficiency in the UK. Energy Policy, 63, 575-587.

Keirstead, J., \& Schulz, N. (2010). London and beyond: taking a closer look at urban energy policy. Energy Policy, 38, 48704879 .

Leaman, A., Stevenson, F., \& Bordass, B. (2010). Building evaluation: practice and principles. Building Research and Information, 38(5), 564-577.

Lomas, K., Bell, M., Firth, S., Gaston, K., Goodman, P., Leake, J., Namdeo, A., Rylatt, M., Allinson, D., Davies, Z., Edmondson, J., Galatioto, F., Brake, J., Guo, L., Hill, G., Irvine, K., Taylor, S., \& Tiwary, A. (2010). The carbon footprint of UK cities. 4M: Measurement, Modelling, Mapping and Measurement. ISOCARP Review 06, International Society of City and Regional Planners (pp. 168-191).

Luque-Martinez, T., \& Muñoz Levia, F. (2005). City benchmarking: a methodological proposal referring specifically to Granada. Cities, 6, 411-423.

MacKay, D. (2009). Sustainable energy-without the hot air. Cambridge: UIT.

Mallaburn, P., \& Eyre, N. (2014). Lessons from energy efficiency policy and programmes in the UK from 1973 to 2013. Energy Efficiency, 7(1), 23-41.

Marchand, R., Koh, S., \& Morris, J. (2015). Delivering energy efficiency and carbon reduction schemes in England: lessons from Green Deal pioneer places. Energy Policy, 84, 96-106.

MET Office (2013). UKCP09 gridded observation data sets [online] http://www.metoffice.gov.uk/climatechange/science/ monitoring/ukcp09/available/annual.html. Accessed 10 Dec2013.

Miles, J., \& Shevlin, M. (2003). Applying regression and correlation: A guide for students and researchers. London: Sage.

Moore, D., McCabe, G., \& Craig, B. (2009). Introduction to the practice of statistics (6th ed., ). New York: W.H. Freeman and Company.

National Grid (2012). Gas demand forecasting methodology. Warwick: National Grid [online] http://www.nationalgrid.com/ NR/rdonlyres/71CFD0F6-3607-474B-9F37-0952404976FB/ 52071/GasDemandForecastingMethodologyFeb12.pdf. Accessed 6 Jul 2014.

Office of National Statistics (2013). Super output areas. [online] http://www.ons.gov.uk/ons/guide-method/geography/ beginner-s-guide/census/super-output-areas-soas-/index. html. Accessed 12 Dec 2013.

Raslan, R., \& Davies, M. (2012). Legislating building energy performance: putting EU policy into practice. Building Research and Information, 40(3), 305-316.

Ren, Z., Paevere, P., \& McNamara, C. (2012). A local-community-level, physically-based model of end-use energy consumption by Australian housing stock. Energy Policy, 48, 586596.

Scott, F., Jones, C., \& Webb, T. (2014). What do people living in deprived communities in the UK think about household energy efficiency interventions? Energy Policy, 66, 335349.

Summerfield, A., Pathan, A., Lowe, R., \& Oreszczyn, T. (2010a). Changes in energy demand from low-energy homes. Building Research and Information, 38(1), 42-49.

Summerfield, A., Lowe, R., \& Oreszczyn, T. (2010b). Two models for benchmarking UK domestic delivered energy. Building Research and Information, 38(1), 12-24.

Swan, L., \& Ugursal, V. (2009). Modeling of end-use energy consumption in the residential sector: a review of modeling techniques. Renewable and Sustainable Energy Reviews, 13, 1819-1835.

Tian, W., Song, J., \& Li, Z. (2014). Spatial regression analysis of domestic energy in urban areas. Energy, 76, 629-640.

Tso, G., \& Yau, K. (2007). Predicting electricity energy consumption: a comparison of regression analysis, decision tree and neural networks. Energy, 32(9), 1761-1768. 
Utley, J., \& Shorrock, L. (2008). Domestic energy fact file 2008. Building Research Establishment. London: Crown Copyright [online] http://www.bre.co.uk/filelibrary/pdf/rpts/Fact_File_ 2008.pdf. Accessed 12 Dec 2014.
Watts, C., Jentsch, M., \& James, P. (2011). Evaluation of domestic energy performance certificates in use. Building Services Engineering Research and Technology, 32(4), 361-376. 